\title{
As dimensões do horror em A Ordem Natural das Coisas
}

Fernando Baião Viotti Universidade Federal de Minas Gerais

\section{Introdução}

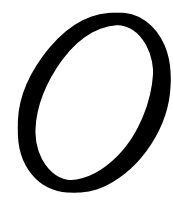

primeiro contato com $A$ ordem natural das coisas, romance do português António Lobo Antunes é uma experiência perturbadora. Desde a primeira página o leitor é lançado sem qualquer rito de iniciação no meio do discurso de um narrador intradiegético que não se apresenta, dando a entrever sua situação imediata apenas por meio de impressões instantâneas do ambiente em que vive, às quais vai mesclando recordações de um passado nebuloso. Ele se dirige à sua companheira Iolanda, mas o leitor logo percebe que seu discurso é silencioso, na verdade um monólogo interior encenado diante da mulher adormecida. Esta narração a partir do ponto de vista específico de uma personagem que revela muito pouco, expressa formalmente a idéia de uma apreensão da realidade lacunar, limitada a um ponto de vista determinado, num procedimento típico do romance moderno.

Esta não será a única fonte de perturbação; a construção formal um tanto sofisticada e difícil de apreender será o meio para construir uma atmosfera de angústia inquietante, um universo pintado com cores sombrias e de personagens retratadas sem qualquer condescendência, nos quais, infelizmente, o leitor contemporâneo não deixará de reconhecer 
o seu mundo e reconhecer-se, ainda que por vias indiretas, caminho por excelência das obras excelentes.

Em que pese a subjetividade de tais efeitos de leitura, decerto que vale a pena tentar decifrar objetivamente a partir do texto quais as especificidades - formais e de conteúdo - que conferem a esta obra alicerçada em requintado trabalho com a linguagem, tal alcance da força expressiva.

\section{O horror do amor}

O romance é dividido em cinco partes, cada uma das quais contendo número variável de capítulos em que duas vozes de narradores-personagens se alternam. Há o companheiro de Iolanda, homem de meia-idade atormentado por um passado nebuloso, vivendo junto a uma mulher que o despreza; Alberto Portas, um ex-agente do governo salazarista, que vive em uma pensão decadente no meio de prostitutas; Jorge, Fernando e Julieta, os aristocratas antepassados do companheiro de Iolanda; uma velha vizinha destes na Calçada do Tojal; Orquídea e o Senhor Oliveira, familiares de Iolanda, entre outras personagens, nem todas nomeadas no decorrer da narrativa.

Difícil estabelecer um protagonista, ou mesmo uma hierarquia rígida entre as diversas personagens, ligadas entre si por fios que vão surgindo gradativamente no decorrer da leitura, através de recordações e fatos parcialmente mantidos na penumbra, o que leva a um entendimento provisório dos acontecimentos narrados, e favorece um clima de incerteza e dúvida que vai se desfazendo sempre aos poucos e nunca completamente.

Tais características por si já mostram a inutilidade de tentar avançar qualquer paráfrase. O entrecho será talvez onde menos resida a força e relevância do livro, muito mais evidente a partir da observação minuciosa de passagens do texto, nas quais Lobo Antunes revela um cuidadoso e peculiar trabalho com a 
linguagem, que nunca resvala para o adorno gratuito, antes funcionando como elemento de construção para situações de alta densidade poética e psicológica.

É nesta chave que se desenrola a primeira parte do livro, em que Alberto Portas, um ex-torturador do regime salazarista e o companheiro de Iolanda se revezam no papel de narradores. Este, personagem sem nome tratado como "velho", "palerma" e "idiota", abre o romance com um monólogo interior que expressa parte da situação terrível que vivencia:

logo que adormeces e uma brancura de olmo com pássaros nos atravessa o quarto, arengo sem que me troces, converso, pairando sobre ti, com as tuas palmas inertes e as tuas coxas indefesas (...) Meu amor, ouve. Talvez me compreendas no teu sono, talvez o teu corpo se liberte da ironia a meu respeito e me queira $(. . .)^{1}$

A solidão, a incomunicabilidade, o desprezo da amada para o amante são os elementos característicos de sua relação com Iolanda. $\mathrm{O}$ amor, tantas vezes refúgio feliz para as agruras cotidianas, ou espaço eloquente em que se encena o drama da paixão, surge aqui desprovido de qualquer élan sublime. O que avulta é a sua dimensão patética, hipertrofiada no apelo resignado do homem diante da mulher que não o ama nem o odeia, lhe votando uma impassível indiferença. A imagem de Iolanda ajuda a bloquear a tonalidade romântica:

Iolanda, amo-te. Amo-te na tua impossibilidade de comer doces, que transformas numa decisão pessoal, numa deliberação altiva, amo as pupilas que começam a embaciarse de cataratas, os rins que sofrem em silêncio, o protesto do pâncreas. $^{2}$

${ }^{1}$ LOBO ANTUNES, 1993, p. 10.

${ }^{2}$ LOBO ANTUNES, 1993, p. 57. 
Adolescente imatura e diabética, Iolanda motiva uma paixão quase grotesca, da qual seu companheiro não consegue se livrar, mesmo consciente da impossibilidade do encontro entre os dois, manifesta em um dos seus monólogos interiores:

A minha idade e os meus bicos-de-papagaio interpõem-se entre nós como um muro que te impede que me estimes, separados por anos e anos de experiências e sustos que não partilhamos, que não poderemos partilhar. ${ }^{3}$

À imaturidade de Iolanda, o seu companheiro não tenta contrapor qualquer atitude superior ou pedagógica por julgá-la inútil, resignando-se à incomunicabilidade a que ambos estão fadados. Há entre os dois um intervalo que a experiência não alcança, limitação tipicamente contemporânea, referenciada por Walter Benjamin em "Experiência e pobreza", no passado, "Sabiase exatamente o significado da experiência: ela sempre fora comunicada aos jovens. De forma concisa, com a autoridade da velhice, em provérbios; de forma prolixa, com a sua loquacidade, em histórias."4

A paixão condenada ao fracasso é apenas um dos traços distintivos da personagem, cujo melhor retrato em todo o livro será talvez aquele pintado pelo ex-torturador Alberto Portas. Apesar de um pouco longo o trecho merece transcrição completa:

(...) enquanto o teu homenzinho, de gabardina e pasta regressa a Alcântara ao encontro do desdém da diabética, aqui o temos na camioneta, aqui o temos atravessando a rotunda, aqui o temos a subir na rampa da Quinta do Jacinto, aqui o temos a agitar os trocos do casaco em busca da chave, aqui o temos a entrar em casa, a cumprimentar a tia e o pai da garota que nem lhe respondem ao sorriso, aqui o temos

${ }^{3}$ LOBO ANTUNES, 1993, p. 57.

${ }^{4}$ BENJAMIN, 1993, p. 114. 
a rumar para o quartinho onde a diabética se afunda no livro de História acompanhada por um colega que lhe rodeia os ombros com o braço, aqui o temos a deixar a pasta junto à cama, fitando a doente e o outro sem notar as mãos de unhas roídas que se tocam sobre o caderno aberto, aqui o temos, amigo escritor, a girar para o quintal das traseiras, com um banco de pedra ao comprido do muro e uma nogueira cujos braços se dobram para o chão, aqui o temos a limpar o assento com o lenço, aqui o temos com a noite de Lisboa crescendo à sua volta, aqui o temos confundido com o muro como a minha voz se confunde com o primeiro crocito de pavão do Campo de Santana, aqui o temos sem esperar nada, sem pensar em nada, sem sentir nada, calado apenas, calado, envelhecido, inerte, tão inerte que nem se dá conta do comboio de Cascais que pula por cima dos jardinzecos da Quinta do Jacinto e lhe cruza o corpo, levando, na fieira de janelas das carruagens, a mudez sem sonhos de que é feito. ${ }^{5}$

A passagem revela muito, tanto pela forma quanto pela substância. Trecho de alta voltagem poética no qual cabe notar o encadeamento anafórico das frases, que contribui para dar um ritmo marcadamente tedioso e rotineiro, corroborando pela forma o que está dito no conteúdo. Saltam à vista as imagens prosaicas compondo a miséria desse sujeito passivo, que vive um sofrimento rés-do-chão desprovido de grandeza, espécie de morte em vida de um homem anulado, incapaz de qualquer ato que o liberte de seu cotidiano opressor ou de seu passado traumático.

Apesar da vida tão comum da personagem, Lobo Antunes constrói para ela uma imagem horrível, uma existência que é essencialmente dor, e será exatamente por essa distinção que ela se aproximará das demais personagens que nos interessa analisar.

${ }^{5}$ LOBO ANTUNES, p. 67. 


\section{Exílio, loucura e trauma}

Na segunda parte do romance, intitulada "Os Argonautas", o foco narrativo se desloca para um outro par de personagens até então aludidos apenas de passagem: o pai de Iolanda, Senhor Oliveira, e sua Irmã Orquídea, que passam a se alternar como narradores durante quatro capítulos.

O elemento de horror, que em algumas passagens chega a tocar o humor negro, reside nas experiências do exílio, da loucura e do sexo, narrados sempre de modo fragmentário, exemplificando bem o modo como o autor se vale de recursos técnicos específicos do discurso literário para se aproximar de seus temas. Assim, a caracterização da loucura aparece com menos força nas referências de Orquídea à demência de seu irmão do que no próprio discurso contraditório que este enuncia.

Suas impressões quase alucinatórias do tempo de trabalho como minerador em Lourenço Marques não traçam, portanto, um retrato consistente da experiência vivida, funcionando antes como instantâneos que permitem apenas entrever o horror, ficando o leitor a cargo de complementar a construção das imagens:

Foi em Joanesburgo, quando voava debaixo da terra de mistura com um cardume de pretos, cada qual com a sua picareta e a sua ampola no capacete, que primeiro me espantei por os cadáveres não aproveitarem o elevador da mina para regressarem, de nardos nos braços e vestidos nupciais à cidade onde nasceram, entrando pela porta da cozinha a desabafarem os tachos do jantar. ${ }^{6}$

Não temos imagens dos mortos, mas a referência do narrador, entrecruzada com a sua própria percepção alucinada,

${ }^{6}$ LOBO ANTUNES, 1993, p. 79. 
faz notar o caráter perturbador de sua experiência, que permanece traumática no momento da enunciação:

Nunca mais voei debaixo da terra, em Joanesburgo, mas ainda me acontece, se adormeço na sala a seguir ao almoço, escutar os mortos que não se atreviam a subir à superfície. ${ }^{7}$

Nem só na lembrança da violência do trabalho nas minas, entretanto, reside o sofrimento do narrador. A África para ele é o espaço do desterro, do "mau cheiro do acampamento dos pretos", e principalmente da mãe de Iolanda, que o Senhor Oliveira conhecera em Lourenço Marques em ocasião não menos mórbida:

(...) conheci a tua mãe num domingo, em novembro, num velório de pobres, a beber martini em torno de um caixão numa vivendinha da ilha (...). Casei uma semana depois com a filha do cadáver. ${ }^{8}$

A órfã então desposada acaba por enlouquecer silenciosamente ao lado do marido, indo terminar esquecida e abandonada por ele em um hospício da capital moçambicana em pleno estouro da guerra civil. Apesar de admitir um melancólico beijo ("ainda pensei em dar-lhe um beijo") durante a despedida no hospício, o Senhor Oliveira regressa a Portugal "sem saudade" e "sem remorso", deixando patente a horrível indiferença que perpassa as relações no mundo sem ternura construído por Lobo Antunes.

Na perspectiva do Sr. Oliveira o retorno a Portugal é o retorno a um espaço idílico, principalmente da infância, cujo mote para recordação é o Minho, nas suas palavras "um presépio de barro na minha memória, com o rio entre faldas de salgueiros

${ }^{7}$ LOBO ANTUNES, 1993, p. 81.

${ }^{8}$ LOBO ANTUNES, 1993, p. 81. 
a separar-me de Espanha". Um refúgio afinal para o horror que perpassa todo o romance? Cabe tentar a resposta para essa pergunta a partir da perspectiva de sua irmã Orquídea.

Conforme já dito anteriormente, o modo de construção de A ordem natural das coisas instaura de maneira indiscutível a multiplicidade de perspectivas e, portanto, uma percepção movente da realidade na medida em que estamos no registro de um ou outro narrador-personagem. Assim, uma "verdade" apresentada inicialmente, ora é completamente transmutada, ora corroborada, ora matizada, conforme o ponto de vista particular que sobre ela se debruça.

Assim, a mãe de Iolanda que para o marido estaria até então contando navios em um hospício de Moçambique, para a cunhada Orquídea teria morrido "do açúcar no sangue no dia seguinte à minha sobrinha nascer." Chama a atenção que ambas as perspectivas sejam incertas, na medida em que inexiste um terceiro narrador hierarquicamente colocado capaz de corroborar uma ou outra versão.

Chama a atenção, sobretudo, que ambas sejam terríveis. Se o espaço da ficção é também com freqüência o espaço da mistificação do acontecimento recordado, não raro se prestando a construir uma alternativa lenitiva para a dor que $o$ fato real motiva, aqui, diante de fato vivido e fato recordado, é difícil qual o mais doloroso; presenciar a morte da esposa após o parto, ou abandoná-la de modo dramático numa distante Moçambique em guerra?

Resulta daí que, por qualquer lado que se olhe, a dor é o sentimento que sempre triunfa, para o qual não há refúgio. Nem mesmo a infância, comumente construída como espaço idílico que resiste ao sofrimento humano, é poupada. Se por um lado o Senhor Oliveira recorda o passado feliz de menino no Minho, para o qual gostaria de retornar após o desterro africano, por outro, o ponto de vista de sua irmã Orquídea faz 
ressaltar justamente a violência e a desilusão que marcaram aquele período.

Além de seu discurso problematizar qual terá sido o verdadeiro destino da mãe de Iolanda em Moçambique, Orquídea apresenta suas memórias sob o peso inescapável de um fato singular, a sua primeira experiência sexual, assim apresentada:

(...) eu esquartejada, nua por dentro contra a parede de lona, sem mais palavras do que uma necessidade absurda, sei lá por quê, de chorar. Vi-o três semanas depois na loja do meu pai e nem me sorriu, nem me falou (...) eu ali, em Esposende, perto dos mil segredos da água, a pensar no que o dono do cinema me tirara e que só valia alguma coisa por ter cessado de existir. ${ }^{9}$

Após trinta e seis anos o momento permanece para Orquídea como experiência da perda e da violência. O dono do cinema, que vende ilusão para o seu público, é o desconhecido que a ilude a se entregar para em seguida desprezá-la, marcando a dimensão sexual da experiência amorosa com um indelével vezo de sofrimento.

As lembranças do Senhor Oliveira mostram que sua irmã não é a única a recordar o passado de maneira dolorosa:

(...) a minha irmã a abraçá-lo e eu a abraçar-me de os ver, a minha irmã a excitar-se e eu a excitar-me de os ver, e por isso, quando o cinema, a lona, os bancos, as caixas dos filmes e o do cigarro partiram para a Póvoa achei-me tão órfão e tão sozinho quanto ela, a farejarmos ambos as estevas estevas estevas... ${ }^{10}$

${ }^{9}$ LOBO ANTUNES, 1993, p. 92.

${ }^{10}$ LOBO ANTUNES, 1993, p. 100. 
Imagem forte até mesmo pela carga de impulso incestuoso que sugere, a confissão do irmão de Iolanda apaga qualquer tom róseo das recordações do passado que pudesse restar. Avulta ainda a indiferença da personagem, que sofre apenas na medida em que se sente perversamente sozinho, já que não tem mais para mirar o objeto de desejo que lhe animava. Na paisagem nebulosa da memória também não há refúgio: o passado também é desilusão, solidão, perversão e horror.

Assim, enquanto cada uma das vozes narrativas vai oferecendo ao leitor novas visadas sobre os fatos já conhecidos, estes vão se recobrindo de novas camadas significativas, em que a experiência da dor é sempre fator determinante. Em que pese a particularidade dos pontos de vista das personagens, $\mathrm{o}$ quadro de sofrimento que poderia ser auto-comiseração, já que pintado através das observações em primeira pessoa, é confirmado, e em alguns casos até mesmo recrudesce.

Bom exemplo é a alcunha de "palerma que paga a renda da casa" dada pelo pai de Iolanda ao companheiro dela, fazendo notar que o desprezo do qual este se queixa não deriva de excessiva suscetibilidade, nem é privilégio apenas de sua mulher, mas compartilhada e referida por todas as personagens que o cercam, compondo a feição de pária tão contundente na caracterização de sua figura construída pelo extorturador Alberto Portas.

\section{O horror da violência}

Na terceira parte do romance, intitulada "Viagem à China", Jorge e Fernando, tios do companheiro de Iolanda são as vozes que se alternam na narração. Jorge é um capitão do exército que termina preso após uma tentativa frustrada de insurreição contra a ditadura salazarista, e o tema central dessa parte do romance será a sua prisão e tortura, experiência 
presente que aparece mesclada a recordações sombrias, tanto do passado distante, como de acontecimentos recentes.

Essa mescla de passado e presente é recorrente em todo o livro, mas aqui será hipertrofiada, na medida em que o discurso do narrador é produzido por uma consciência perturbada, que está sob o efeito da tortura. Não é fácil compreender nem demonstrar o modo como o autor realiza tal expressão através de recursos literários, mas vale a pena, entretanto, tentar a explicação. Será necessário nesse caso recorrer a grifos, sem os quais a compreensão do trecho analisado, já difícil dentro do contexto da leitura, se tornaria impossível com o seu destaque do todo:

O comodoro Capelo era da conjura, farteime de conspirar na Costa da Caparica,

e o careca $\underline{\mathrm{O} \text { senhor Comodoro Capelo, atuando }}$ com o nosso acordo e enviando-nos relatórios mensais, fingiu ser democrata e aturou-vos as asneiras por amor ao Regime

(...)

Ao senhor comodoro emprenhei-lhe a puta da filha, suspirei eu debaixo do sapato do Nicolau, só não lhe comi a esposa por ser um monte de banhas,

(...)

"Pede desculpa, corno, se calhar estou grávida, em todas as famílias há uma ovelha ranhosa, que te mato aquii",

ou então vamos a Buarcos, Margarida, conheço um restaurante sobre a praia, já viste as arvéolas nas arribas, viste as algas, viste as figueiras pelo mar acima, o odor das folhas, o leite grosso dos frutos?

leite branco, leite como o meu sangue, como a alegria, como o medo que sinto, branco, branco, o senhor 


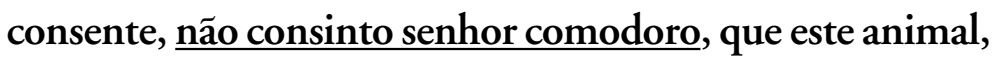
temos um homem de confiança em Penafiel para o transportar a Espanha, me insulte,"11

Trata-se de um caleidoscópio que pode ser tomado como amostra de toda a narração de Jorge no momento da tortura, um discurso entrecortado, que vai mesclando passado e presente e as vozes de várias personagens. Essa estrutura caótica se potencializa na medida em que avança a tortura da personagem, compondo em nível formal a perturbação discursiva que é fruto de uma consciência também perturbada. O resultado é a concretização magistral - pelos recursos narrativos - da própria matéria narrada, qual seja o estado de confusão mental causado pela violência a que a personagem está submetida. Não faltam passagens em que essa violência irrompe em primeiro plano:

Depois de cinco ou seis semanas

(ou dez ou doze ou vinte, quem me responde a isto, Margarida?)

a urinar sangue na enfermaria do Forte Caxias, com a bexiga repleta de pedacinhos de vidro,

(pedacinhos de vidro, mãe)

${ }^{11}$ LOBO ANTUNES, 1993, p. 126, 127.

Normal sublinhado: voz de Jorge

Negrito sublinhando: voz do homem que o interroga

Itálico sem sublinha: voz da filha do Comodoro, recordada por Jorge

Normal sem sublinha: impressões de Jorge, em que passado e presente se misturam.

Negrito sem sublinha: voz do Comodoro.

Itálico com sublinha: voz do coronel Gomes, correligionário de Jorge, recordada por Jorge. 
mudaram-me para uma cela no piso inferior da cadeia onde eu procurava adivinhar as horas segundo a tonalidade do céu, escarlate, azul, pálido, branco, completamente negro, $(. . .)^{\prime \prime 12}$

Aqui estamos na dimensão do horror mais concreto, originado não de um trauma do passado, nem da angústia do amor, mas da degradação física e psicológica deliberadamente infligida. Essa violência recrudesce, fazendo recrudescer também o horror, que deriva não só dela, mas ainda da derrota enfim imposta ao democrata Jorge:

um dos homens ligou o aparelho à corrente, uma ampola acendeu-se, uma agulha vibrava, um segundo homem acercou-se de mim com os eletrodos e o inspetor $\mathrm{A}$ identificação dos revolucionários já, (...)

o primeiro homem carregou num botão e o corpo esticou-se-me, os dentes estralejaram, a cabeça voou para longe do pescoço, o coração, repleto de hélio, suspendeuse antes de recomeçar a trabalhar,

Socialista, senhor, socialista, Monsanto tão verde, o quarto da Amália, nunca fui socialista,

Claro que não foste, assentiu o inspetor, claro que não foste, outra vez,

e de novo o corpo a pular, de novo o estralejar dos dentes, de novo a cabeça solta do pescoço, de novo o coração vogando e o sangue parado, à espera,

Outra vez, pediu o inimigo da violência (...)

gritei-lhes na cara o que desejavam conhecer, isto é, que o meu pai escondia a minha irmã Julieta com raiva e vergonha de não ser dele $(. . .)^{13}$

12 LOBO ANTUNES, 1993, p. 139.

${ }^{13}$ LOBO ANTUNES, 1993, p. 141. 
A extrema violência sofrida pela personagem culmina numa explosão de desespero. A frase final encerra uma ambigüidade, pois o narrador emenda a "o que desejavam conhecer", um fato do passado que o perturba, obviamente sem qualquer relação com aquilo que seus torturadores "desejam saber". O desenrolar dos fatos nos próximos capítulos, entretanto, como sua condenação e a de seus correligionários, ou a discussão com seus advogados acerca da admissão da culpa, aponta de fato para uma capitulação, que permanece, no entanto, não admitida pelo narrador. É a morte, afinal, da consciência. $O$ paranóico discurso de Jorge que se desenvolve a partir de então dá a medida da loucura a que a violência o faz sucumbir.

Essa parte do romance contém decerto um diferencial de ênfase na apresentação do horror, dada principalmente pelas fortes imagens de violência que contém. Não se percebe, entretanto, uma diferença de tom capaz de estabelecer uma hierarquia em relação aos capítulos anteriores. $\mathrm{O}$ sofrimento heróico do capitão do exército não surge mais destacado do que a dor comezinha do pacato suburbano. A própria estrutura do romance, em que as vozes narrativas dispõem praticamente do mesmo espaço e se enunciam no mesmo nível, sugere essa indistinção. No universo de Lobo Antunes, o horror parece ser uma força motriz que perpassa tudo, da qual nunca se encontra escape.

\section{Perspectivas críticas}

Em seu recente Redemunho do Horror, Luiz Costa Lima observa as manifestações da experiência do horror na literatura desde os relatos portugueses da expansão marítima até a literatura latino-americana moderna, passando demoradamente por Joseph Conrad, o arquiteto do horror por excelência. $\mathrm{Na}$ introdução ao seu estudo destaca duas modalidades básicas de 
horror, uma seria aquela dos continentes marginalizados, enquanto a segunda é o horror gerado na Europa e desenvolvido nos Estados Unidos. Costa Lima assim os diferencia:

Ao passo que o primeiro é basicamente o horror provocado por condições sociais que favorecem a violência física e relaciona-se com a dependência, o atraso e a instabilidade político-econômica, o segundo como já se mostra no Madame Bovary (1857) é motivado pelo tédio, pela angústia, pela falta de sentido de uma ambiência no entanto tranqüila; o horror basicamente do mal-estar psíquico, de que Samuel Beckett (1906-1989) seria o outro pólo. ${ }^{13}$

A consideração de Costa Lima parece encorajar uma interessante articulação com os pontos analisados a propósito do romance de Lobo Antunes. Conforme vimos tentando demonstrar durante a análise da obra, em A Ordem Natural das Coisas a experiência do horror surge como uma constante que se movimenta e se altera em meio a muitas variáveis. Ora estamos no espaço urbano industrializado, ora em meio à guerra civil em África, ora um casal incompatível se debate ante o próprio mal-estar, ora um capitão revolucionário sofre insuportáveis maus-tratos físicos e psicológicos. O horror, entretanto, surge indistinto tanto do sofrimento heróico daquele que quer resistir à tortura mas fracassa, como do cotidiano sombrio dos moradores do subúrbio.

Ou seja, em Lobo Antunes não há uma diferenciação nítida de espaços para uma ou outra experiência. O horror perpassa tudo, não respeitando qualquer ditame geográfico, cultural ou sócio-político. Cabe lembrar que o próprio Costa Lima adverte mais adiante para o quanto móvel pode ser a expressão das duas modalidades que destaca:

${ }^{13}$ COSTA LIMA, 2003, p.18. 
(...) a diferença entre as modalidades de horror não está presa a alguma causalidade mecânica e rasteira. Mas isso não impede que essas modalidades se distingam! Mesmo que seja apenas pela dominância do grau de violência, física em um caso, psíquica no outro. ${ }^{14}$

A observação é perfeitamente válida para as obras sobre as quais o crítico se debruça, o que aumenta o interesse de sua formulação em relação ao romance de Lobo Antunes, no qual parece ser impossível falar em ênfase de uma modalidade ou outra. O que motivaria essa posição peculiar do romance em face das obras abordadas por Costa Lima? Cabe lembrar que o crítico elabora sua diferenciação com base em um condicionamento socio-político, destacando a influência do meio como fator decisivo, nesse caso o meio em que a narrativa se localiza, não aquele em que é engendrada. A formulação parece efetivamente legítima, e se a transportamos para a interpretação aqui desenvolvida ela talvez mantivesse sua aplicabilidade criando um terceiro espaço no qual o romance de Lobo Antunes se encaixaria.

Enquanto na análise de Costa Lima temos dois espaços delimitados com certa nitidez - de um lado os continentes marginalizados para a expressão do horror físico, e do outro o eixo Europa-Estados Unidos para a expressão do horror psíquico - o Portugal das décadas de 1970-1990, localização espaçotemporal em que se desenrola a narrativa de Lobo Antunes, surgiria como um terceiro local em que convergiriam esses dois extremos, a partir de fatores de ordem principalmente política.

Enumere-se, por exemplo, o declínio final do império português com a perda das últimas colônias; e a Revolução dos Cravos pondo fim a décadas de ditadura salazarista, mas ao mesmo tempo incapaz de alterar significativamente a posição

${ }^{14}$ COSTA LIMA, 2003, p. 22. 
paradoxal que a envelhecida nação portuguesa ocuparia neste momento específico em face de uma Europa freneticamente moderna. Enfim, a envergonhada pobreza lusitana contrastando com a cada vez mais opulenta riqueza das demais nações européias.

Trata-se afinal de contas do "alheamento, pelo menos relativo, do movimento geral da civilização e da cultura européia", que Eduardo Lourenço aponta especificamente nos séculos XV e XVI, ${ }^{15}$ mas que perduraria até então.

Esse Portugal ao mesmo tempo "margem" e "centro", surgiria, portanto, hipoteticamente como lugar em que o horror físico e o horror psíquico convergem e convivem sem distinção. Sugestão decerto problemática, que mereceria um desenvolvimento mais aprofundado capaz de demonstrá-la a contento, mas que fica, de qualquer maneira, proposta como possibilidade interpretativa.

\section{Horror e resistência}

Diz João Barrento que a Europa contemporânea é espreitada por um fantasma. Segundo o português, "Este fantasma, que não nos assombra as existências porque alguém hoje se encarrega sempre de o fechar no quarto dos fundos...é a dor."16 Para ele as sociedades ocidentais tentam varrer o sofrimento para debaixo do tapete, e o fazem não raro recorrendo à expressão artística:

(...) perdeu-se nas nossas sociedades a capacidade de luto, esta exilou-se para uma exígua região onde só alguns dão por ela, a da arte. ${ }^{17}$

${ }^{15}$ LOURENÇO, 1999, p. 95.

16 BARRENTO, 2001, p. 68.

17 BARRENTO, 2001, p. 69. 
A afirmação encerra decerto um paradoxo. O homem teria se tornado incapaz de expressar e vivenciar o seu sofrimento, a não ser por meio do artifício da expressão artística. Por outro lado, ao conceber obras onde a dor e a morte aparecem como elementos centrais, $\mathrm{o}$ artista traz à tona sentimentos comumente escamoteados no espaço dos discursos não-literários. A reflexão pode levar a um dilema.

É possível imaginar que o artista faz da dor o protagonista da obra, para se contrapor ao seu apagamento asséptico na dimensão da realidade, alertando desse modo para o caráter inelutável de sua presença. Mas é possível também ver aí uma atitude pragmática que concretiza a dor no espaço da arte para que possamos evitá-la no cotidiano.

Talvez as duas proposições sejam verdadeiras, e a causalidade que porventura as une seja impossível de estabelecer. $O$ fato é que a literatura, que desde Homero se interessa pelo sofrimento humano, permanece como meio privilegiado de expressão para nossas agruras, e nesse quesito Lobo Antunes surge decerto como um dos maiores expoentes da atualidade, $\mathrm{e}$ o faz decerto pela dimensão do contraponto.

As diferentes modulações da experiência do horror que tentamos destacar no romance, enfatizam a crueza e a inevitabilidade com que se impõem, afirmando uma desilusão que não condescende com nada, como se desejassejogar na face do leitor a dor que os discursos convencionais tencionam escamotear.

Num mundo onde a dor não está em lugar algum, Lobo Antunes apresenta um outro em que o horror deriva da presença da dor em todos os lugares. Não se resume ao exílio vivido em condições sub-humanas em Joanesburgo ou Moçambique; não está confinada na mente atormentada de loucos perseguidos por espectros imaginários; não é o passado que vem cobrar o tributo dos que se omitiram nem o cotidiano opressor que sufoca os que ainda então se omitem. O horror se vive igualmente no amor e 
no sexo, na infância e na velhice, no nascimento de uma criança que pode ser a morte de sua mãe, e na morte que não significa nunca qualquer possibilidade de transcendência ou renascimento. Não é o horror psíquico dos espaços urbanos, nem o horror físico dos ambientes hostis à civilização.

As imagens horríveis não derivam apenas de experiências limite como a tortura, o exílio e a loucura. Ainda que estas também sejam matéria da narrativa, o autor não as localiza hierarquicamente acima dos dramas banais do cotidiano. Essa apresentação do horror como algo de que é impossível escapar, faz relevante contraste com a perspectiva hedonista pós-moderna de obliterar a dor, conferindo à obra um caráter de negação da doxa banalizada. Tais escolhas impulsionam a obra ao encontro do conceito formulado por Alfredo Bosi em Literatura e Resistência:

Os escritos de ficção, objeto por excelência de uma história da literatura, são individuações descontínuas do processo cultural. Enquanto individuações, podem exprimir tanto reflexos (espelhamentos) como variações, diferenças, distanciamentos, problematizações, rupturas e, no limite, negações das convenções dominantes no seu tempo. ${ }^{18}$

Ao desenvolver a idéia o crítico confere à questão um juízo de valor, afirmando que as grandes obras, mais do que refletirem, questionam a realidade em que se inserem. Por esse critério convém afirmar que esse é um dos pontos a que se prende a qualidade deste romance de António Lobo Antunes, na medida em que o autor constrói uma atmosfera eloquentemente grave, a partir de uma perspectiva crítica tenaz, capaz de se contrapor à leve e descomprometida apreciação superficial da realidade levada a cabo, sobretudo, pelos mass media predominantes em nosso tempo, TV e Internet à frente.

${ }_{18}$ BOSI, 2002, p. 10. 
Para concluir, cabe advertir o caráter provisório das correlações traçadas entre a obra e os pressupostos críticos expostos nesta segunda parte, na medida em que estes contêm em sua base um decisivo viés historiográfico, difícil de aplicar ao objeto específico que é a obra de Lobo Antunes. Até mesmo pelo fato de o autor - felizmente - se encontrar em plena atividade, dificultando o distanciamento crítico indispensável para aprofundar tais proposições.

\section{Referências}

BARRENTO, João. Receituário da dor para uso pós-moderno. In: $A$ espiral vertiginosa. Lisboa: Cotovia, 2001.

BENJAMIN, Walter. Experiência e pobreza. In: Obras escolhidas vol. I: magia e técnica, arte e política. São Paulo: Brasiliense, 1994.

BOSI, Alfredo. Por um historicismo renovado: Reflexo e reflexão em história literária. In: Literatura e resistência. São Paulo: Companhia das Letras, 2002.

COSTA LIMA, Luiz. O redemunho do horror: as margens do ocidente. São Paulo: Planeta do Brasil, 2003.

LOBO ANTUNES, António. A ordem natural das coisas. Rio de Janeiro: Rocco, 1993.

LOURENÇO, Eduardo. Portugal como destino. In: Mitologia da Saudade. São Paulo: Companhia das Letras, 1999. 


\section{Resumo}

Este ensaio é uma análise de $A$ ordem natural das coisas de Antonio Lobo Antunes, no qual se tenta desentranhar da estrutura formal peculiar da narrativa, os temas do horror, da loucura e da morte abordados no romance. Articulando as significações de fundo e de forma, o ensaio procura mostrar como o romance enfatiza a dimensão trágica da experiência humana, e o choque que essa ênfase provoca quando posta em face do hedonismo superficial predominante no modus vivendi contemporâneo.

\section{Abstract}

This essay is an analysis of A ordem natural das coisas, by Antonio Lobo Antunes. It attempts to investigate the particular formal structure of this narrative, focusing on the themes of horror, madness and death, depicted in the novel. Mixing the meanings of the novel's thematic and its formal structure, the essay intends to show how the novel expresses the tragic side of human experience, and how this emphatic approach is in shock with the comtemporary superficialism typical of our times. 
